\title{
Computer analysis of thermal phenomena and deformation in lap joint welded by a laser beam
}

\author{
Wiesława Piekarska ${ }^{1}$, Alžbeta Sapietová $^{2}$, Zbigniew Saternus ${ }^{1, *}$, Marcin $_{\text {Kubiak }}{ }^{1}$ \\ ${ }^{1}$ Czestochowa University of Technology, Faculty of Mechanical Engineering and Computer Science, \\ Czestochowa, Poland \\ ${ }^{2}$ University of Žilina, Faculty of Mechanical Engineering, Žilina, Slovak Republic
}

\begin{abstract}
Laser welding technology is applied to many types of welded joints. The determination of the influence of technological parameters on the properties of resulting joint is a significant problem for technologists. Numerical estimation of the shape of the weld and its deformation is important in the initial stage of construction design. The paper concerns computer analysis of thermal and mechanical phenomena in laser welded lap joint made of austenitic steel. Three dimensional discrete model of analyzed lap joint is created in Abaqus FEA engineering software. Numerical analysis takes into account temperature dependent thermomechanical properties of austenitic steel. The movable heat source power distribution is modelled using Gaussian distribution. Computational model takes into account the gap between the joined plates. Temperature distribution in analysed joints is presented on the basis of performed numerical simulations. The shape and size of the fusion zone as well as deformation of the joint are estimated.
\end{abstract}

Keywords: Laser welding, numerical modelling, lap joint, welding deformation

\section{Introduction}

The application of laser technology in the production process opened new possibilities for using of welding in many industries. The main advantage of using laser welding techniques is the increase of the efficiency of the welding process and the possibility of automation and robotization of the process [1-3]. Laser beam welding technology is currently widely used in the manufacture of innovative welded constructions [4-6]. However, this welding method is related to many new, unknown issues that designers must contend. The heat distribution is completely different in laser welding in comparison to conventional, well known electric arc processes $[5,7,8]$. Other important issue is welding deformation that occurs in welded elements. In available literature the deformation depends mainly on the amount of heat input to the material during welding processes [2, 9-11]. The use of a laser heat source significantly minimizes the impact of heat load on the weldment which contributes to smaller welding deformation $[7,8]$. Laser beam welding is used to perform various types of joints, including lap joints $[3,4,6]$. Lap joints are used in many industries, including the automotive industry and the aerospace industry.

*Corresponding author: saternus@imipkm.pcz.pl

Reviewers: Františka Pešlová, Ján Vavro 
Recently, research centers and design offices use numerical methods to evaluate the accuracy of construction design at the initial stage of production process [12-14]. A proper mapping of the real process in a computational program and the assumption of appropriate mathematical and numerical models has a significant impact on the quality and reliability of obtained results $[7,8]$.

Numerical analysis of laser welding of lap joint made of austenitic steel X5CrNi18-10 is carried out in this study. Numerical calculations are performed in the Abaqus computational software on the basis of the use of finite element method (FEM). A three dimensional discrete model of the discussed system is developed with temperature dependent thermophysical properties of analyzed steel taken into account. In order to adapt the Abaqus for the simulation of welding processes the implementation of additional numerical subroutines is necessary. Subroutines are written in a FORTRAN programming language. The numerical subrotines allows to model a moveable heat sources with a specific power distribution. Appropriate contact conditions are assumed in the model at the interface between joined elements. Temperature distribution and size of the melted zone as well as stress state and deformation in the laser welded lap joint are estimated on the basis of performed numerical simulations.

\section{Numerical modeling of thermal and mechanical phenomena in Abaqus program}

The numerical analysis of the lap joint welding process in the Abaqus program is divided into two steps. The first step involves conducting numerical analysis of thermal phenomena. An analysis of mechanical phenomena is then performed on the basis of results obtained in the first step of calculations. Schema of the analysis is shown in Figure 1.

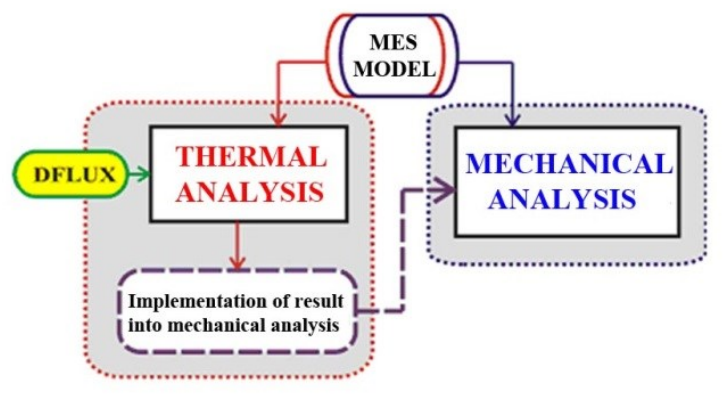

Fig. 1. Thermomechanical analysis diagram in Abaqus FEA

\subsection{Analysis of thermal phenomana}

The differential governing equation of temperature field in the Abaqus software is based on the energy conservation equation with Fourier's law $[8,15]$. Simulations are carried out in Lagrange's coordinates, where coordinates of the center of heat source $x=v \cdot t$ is defined for every time increment $t[\mathrm{~s}]$, depending on the welding speed $v[\mathrm{~m} / \mathrm{s}]$. Temperature field is expressed in the criterion of weighted residuals method as follows:

$$
\int_{V} \rho \frac{\partial U}{\partial t} \delta T d V+\int_{V} \frac{\partial \delta T}{\partial x_{\alpha}} \cdot\left(\lambda \frac{\partial T}{\partial x_{\alpha}}\right) d V=\int_{V} \delta T q_{V} d V+\int_{S} \delta T q_{S} d S
$$


where $\lambda$ is a thermal conductivity $\left[\mathrm{W} / \mathrm{m}^{\circ} \mathrm{C}\right], U=U(T)$ is a internal energy $[\mathrm{J} / \mathrm{kg}], q_{v}$ is a laser beam heat source $\left[\mathrm{W} / \mathrm{m}^{3}\right], T=T\left(x_{o} t\right)$ is a temperature $\left[{ }^{\circ} \mathrm{C}\right], q_{s}$ is a boundary heat flux $\left[\mathrm{W} / \mathrm{m}^{2}\right], \delta T$ is a variational function, $\rho$ is a density $\left[\mathrm{kg} / \mathrm{m}^{3}\right], T=T\left(x_{\theta}, t\right)$ is temperature $\left[{ }^{\circ} \mathrm{C}\right]$.

Equation (1) is completed by the initial condition $t=0: T=T_{0}$ and boundary conditions of Dirichlet and Neumann type. Newton type condition with the heat loss due to convection, radiation and evaporation [16].

During the thermal phenomena analysis of laser welding process of the lap joint, free contact between joined elements is assumed. Therefore, it is necessary to define the thermal contact between the joined elements $[10,17,18]$. The heat flow at the interface between the two bonded elements is described by the Fourier law taking account of the contact resistance $r_{s}$. Applying the fourth type of boundary condition causes continuity of temperature distribution and heat flux [16]. The scheme of the considered system is shown in Figure 2. In the discussed system, two separate systems A and B were connected to the common temperature $T_{C}=T_{o t}$.

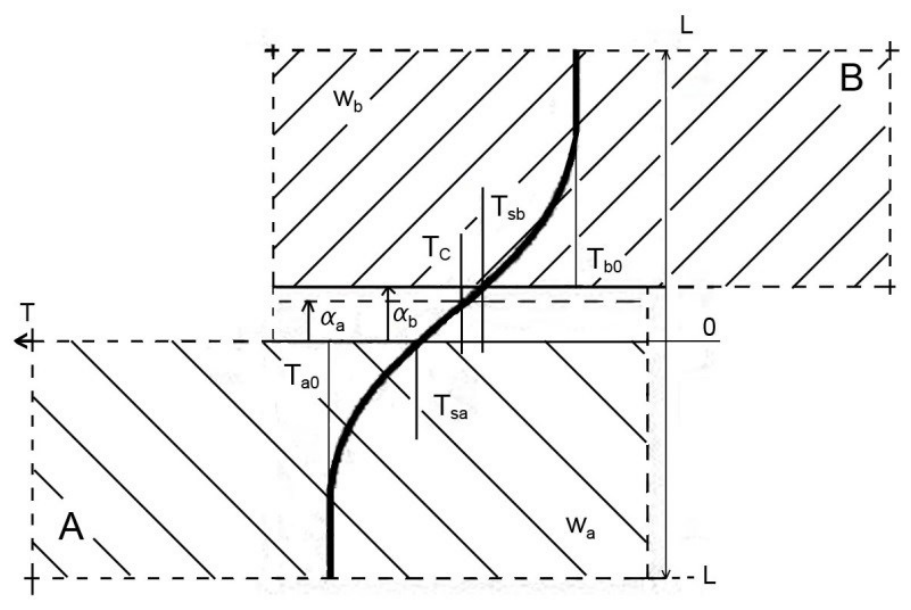

Fig. 2. Scheme of the analysis of thermal phenomena taking into account the gap between the two elements

The fourth type of boundary condition with the contact resistance $r_{s}$ included can be written as [17]:

$$
\lambda_{a}\left(\frac{\partial T_{a l}}{\partial l_{a}}\right)_{s A}=\lambda_{b}\left(\frac{\partial T_{b l}}{\partial l_{b}}\right)_{s B}=\frac{T_{a l}-T_{b l}}{r_{s}}
$$

where $T_{a l}, T_{b}$ are respectively the temperature in the areas A and $\mathrm{B}\left[{ }^{\circ} \mathrm{C}\right], T_{a 0}, T_{b 0}$ initial temperature in the area $\mathrm{A}$ and $\mathrm{B}\left[{ }^{\circ} \mathrm{C}\right], t$ is time $[\mathrm{s}], \alpha_{a}, \alpha_{b}$ are coefficients of temperature equalization in areas $\mathrm{A}$ and $\mathrm{B}\left[\mathrm{m}^{2} / \mathrm{s}\right], \lambda_{a}, \lambda_{b}$ are thermal conductivity of the area $\mathrm{A}$ and $\mathrm{B}$ $\left[\mathrm{W} / \mathrm{m}^{\circ} \mathrm{C}\right]$.

Fuzzy solidification front is assumed in the model [8]. Solidus and liquidus temperatures are set to $T_{S}=1400^{\circ} \mathrm{C}$ and $T_{L}=1455^{\circ} \mathrm{C}$, whereas latent heat of fusion $H_{L}=260 \times 10^{3} \mathrm{~J} / \mathrm{kg}$.

Modeling of the moveable welding source in the Abaqus is done using DFLUX subroutine. The most commonly adopted Gaussian heat source model is used in the research. The accepted model assumes a linear decrease of energy density along material penetration depth [19]. 


$$
q_{v}(r, z)=\frac{Q \cdot \eta}{\pi r_{o}^{2} s} \exp \left[\left(1-\frac{r^{2}}{r_{o}^{2}}\right)\right]\left(1-\frac{z}{s}\right)
$$

where $Q$ is a laser beam power [W], $r_{0}$ is a beam radius [m], $r=\sqrt{x^{2}+y^{2}}$ is actual radius $[\mathrm{m}], s$ is penetration depth $[\mathrm{m}], z$ is actual penetration $[\mathrm{m}]$.

\subsection{Analysis of mechanical phenomana}

The mechanical analysis in elastic-plastic range is based on classic equilibrium equations, supplemented by constitutive relations $[7,20]$ :

$$
\begin{gathered}
\nabla \circ \dot{\boldsymbol{\sigma}}\left(x_{\alpha}, t\right)=0, \quad \dot{\boldsymbol{\sigma}}=\dot{\boldsymbol{\sigma}}^{T} \\
\dot{\boldsymbol{\sigma}}=\mathbf{D} \circ \dot{\boldsymbol{\varepsilon}}^{e}+\dot{\mathbf{D}} \circ \boldsymbol{\varepsilon}^{e} \\
\boldsymbol{\sigma}\left(x_{\alpha}, t_{0}\right)=\boldsymbol{\sigma}\left(x_{\alpha}, T_{S}\right)=0, \quad \boldsymbol{\varepsilon}^{e}\left(x_{\alpha}, t_{0}\right)=\boldsymbol{\varepsilon}^{e}\left(x_{\alpha}, T_{S}\right)=0
\end{gathered}
$$

where $\boldsymbol{\sigma}=\boldsymbol{\sigma}\left(\sigma_{i j}\right)$ is stress tensor, $x_{\alpha}$ describes location of considered point (material particle), ( $\circ)$ is inner exhaustive product, $\mathbf{D}=\mathbf{D}(\mathrm{T})$ is a tensor of temperature dependent material properties.

The total strain is defined as a sum of elastic $\varepsilon^{e}$, plastic $\varepsilon^{p}$ and thermal $\varepsilon^{T h}$ strains:

$$
\varepsilon^{\text {total }}=\varepsilon^{e}+\varepsilon^{p}+\varepsilon^{T h}
$$

Elastic strain is modelled using an isotropic Hooke's law, whereas plastic strain is calculated using plastic flow model obeying Huber-Misses plasticity condition [20].

In the case of numerical analysis of laser welding lap joint, it is necessary to define the mechanical interaction between two joined materials. As a result of mechanical interactions, the contact area of the two elements is deforming. Boundary conditions assumed in mechanical analysis are prescribed for preventing rigid body motion.

\section{Discrete model}

Three dimensional discrete model of analyzed lap joint is developed in Abaqus CAE software. The analyzed joint consists of two plates made of austenitic steel X5CrNi18-10 whith dimensions $50 \times 20 \times 1.5 \mathrm{~mm}$. The model assumes that the welded plates overlap on the length $25 \mathrm{~mm}$. Scheme of the analyzed system is shown in Figure 3. 


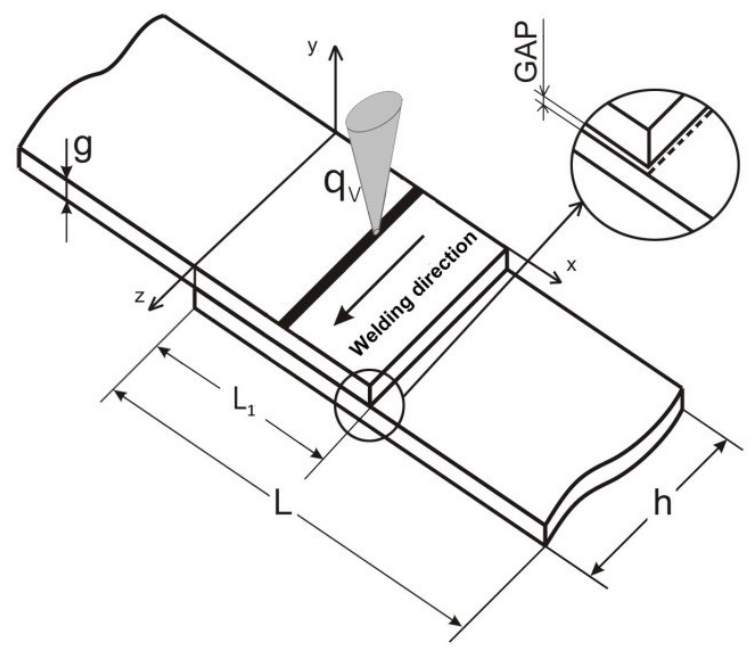

Fig. 3. Scheme of analyzed system

Perfect contact between the connected elements is assumed at the melted zone in the developed discrete model of the lap joint. Further, outside the melting zone, free contact between joined elements is assumed. The width of the melting zone at the welded plates is determined on the basis of pre-made simulation calculations. The gap between welded plates in the remaining area is $0.1 \mathrm{~mm}$. The discrete model consists of 30.000 finite elements. Due to the high temperature gradient that occurs at the welding source activity zone the high density of the finite element mesh is assumed (Figure 4).

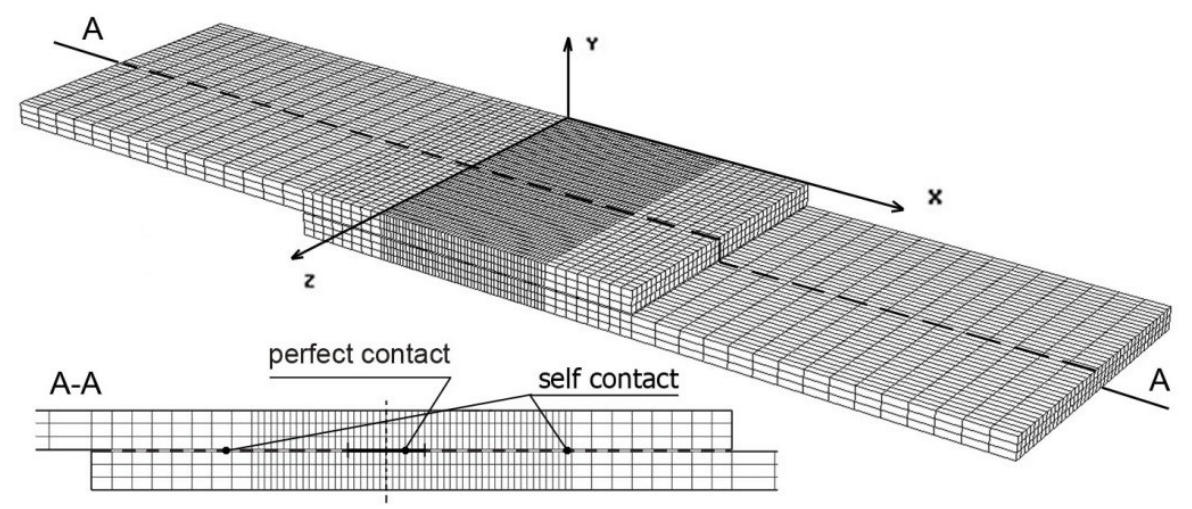

Fig. 4. Discretization of analyzed domain

Assumed thermomechanical properties of austenitic steel changing with temperature are presented in Figure 5 [8]. 

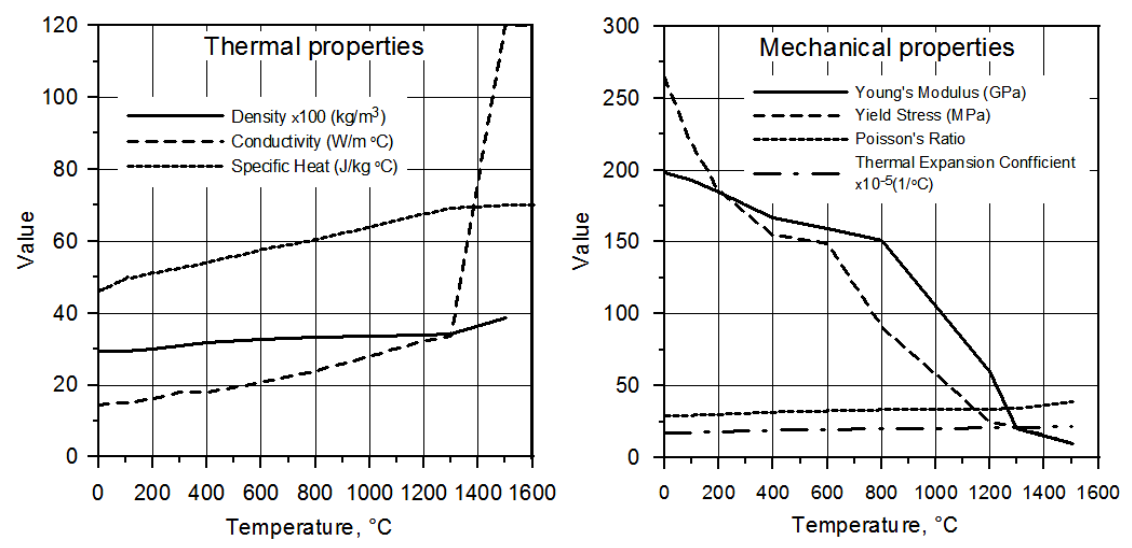

Fig. 5. Thermomechanical properties of $\mathrm{X} 5 \mathrm{CrNi1}$ 8-10 stainless steel

\section{Results and discussion}

Numerical calculations of the laser welding process of lap joints are performed in the Abaqus simulation program. In calculations, the efficiency of the laser beam welding process is assumed on the basis of literature data as $\eta=75 \%$. Process parameters assumed in calculations are summarized in Table 1.

Table 1. Process parameters used in computer simulations

\begin{tabular}{|c|c|c|c|}
\hline Laser beam power & Welding speed & Beam radius & Penetration deep \\
\hline$Q=1500 \mathrm{~W}$ & $v=0.7 \mathrm{~m} / \mathrm{min}$ & $r_{0}=1 \mathrm{~mm}$ & $s=4 \mathrm{~mm}$ \\
\hline
\end{tabular}

In the case of the analysis of thermal phenomena with the free contact taken into account it is necessary to define the appropriate interaction condition. Thermal conductivity in the contact area of both elements must be defined The calculation program determines the conductivity as a function of the gap width [15].

Temperature field in analyzed joints are estimated on the basis of performed numerical simulations. Figure 6 shows the temperature field in welded lap joint, while Figure 7 shows distribution of temperature field in the cross-sectional area. In these figures the solid line indicates the boundaries of the melting zone. 


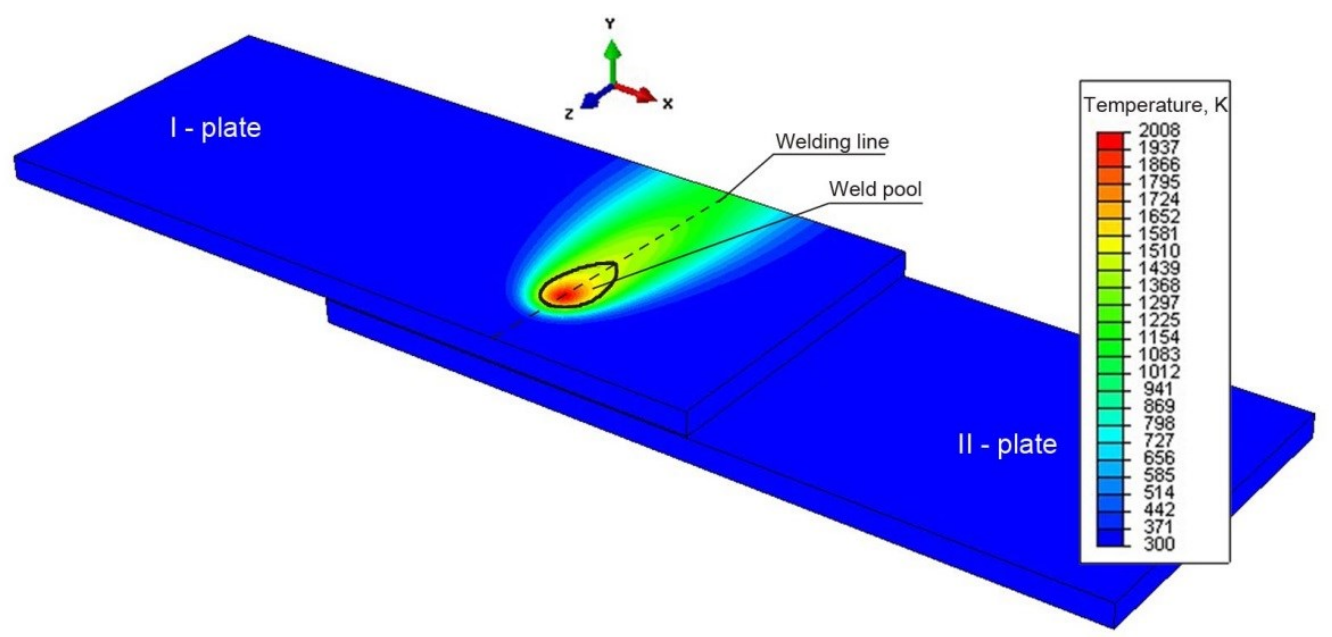

Fig. 6. Numerically estimated temperature field in laser welded lap joint

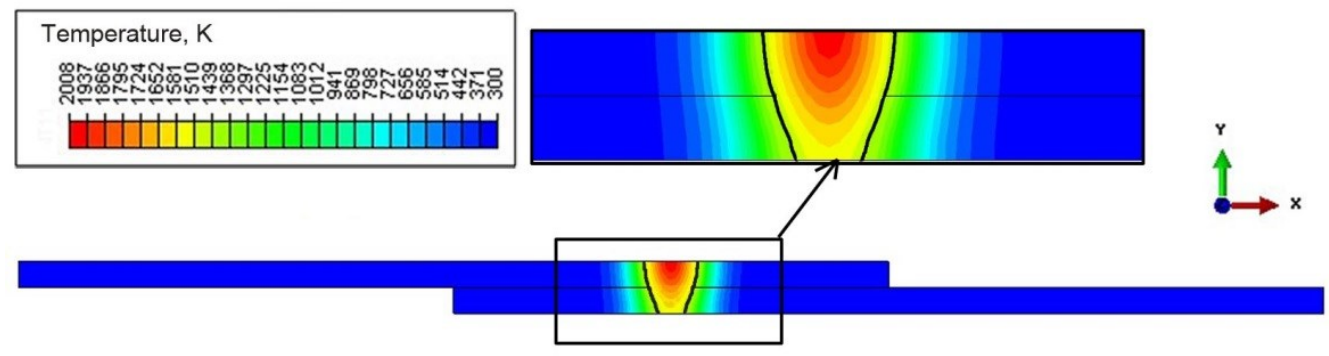

Fig. 7. Temperature field in cross section of the welded lap joint

On the basis of obtained temperature distributions, the state of stress and displacement of welded elements is determined. The developed numerical model takes into account the mechanical boundary conditions (Fig. 8) for two analyzed cases and contact conditions between welded parts.
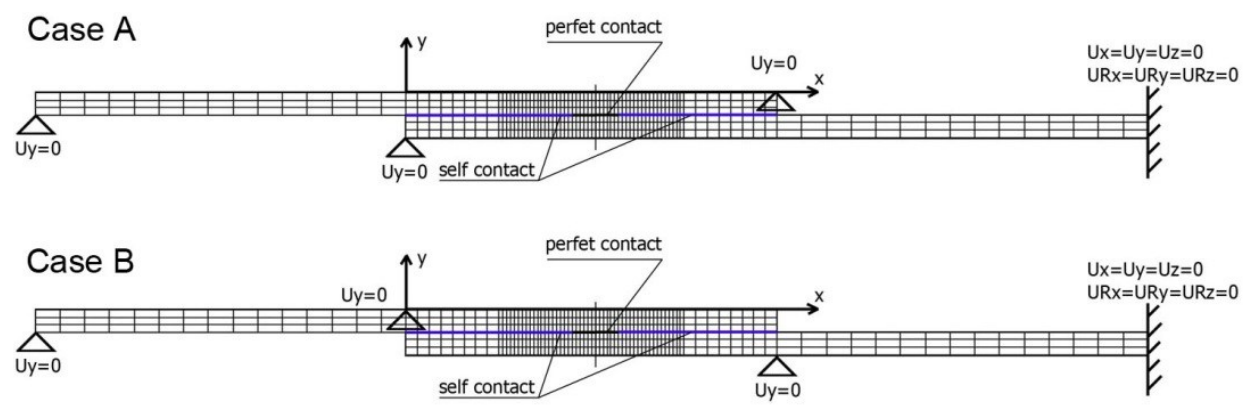

Fig. 8. Mechanical boundary conditions

Figure 9 shows the distribution of temporary and residual stresses for two different cases of support. The maximum value of residual stresses is about $170 \mathrm{MPa}$. 
a)

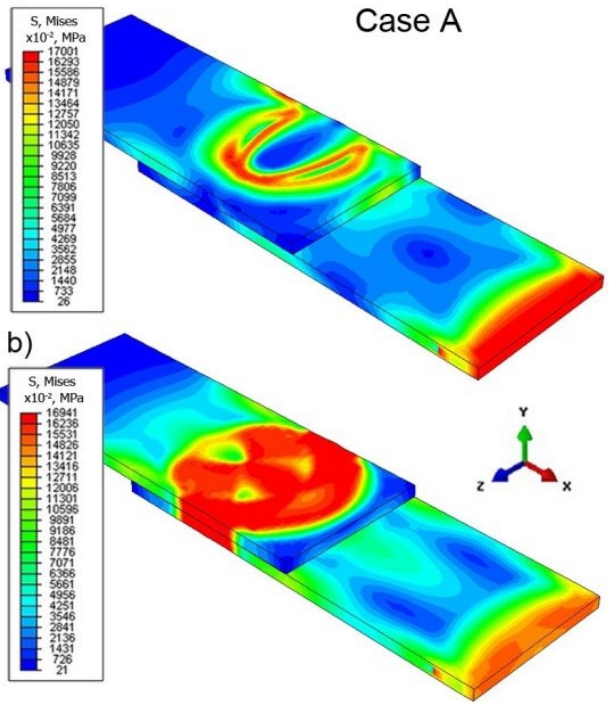

a)

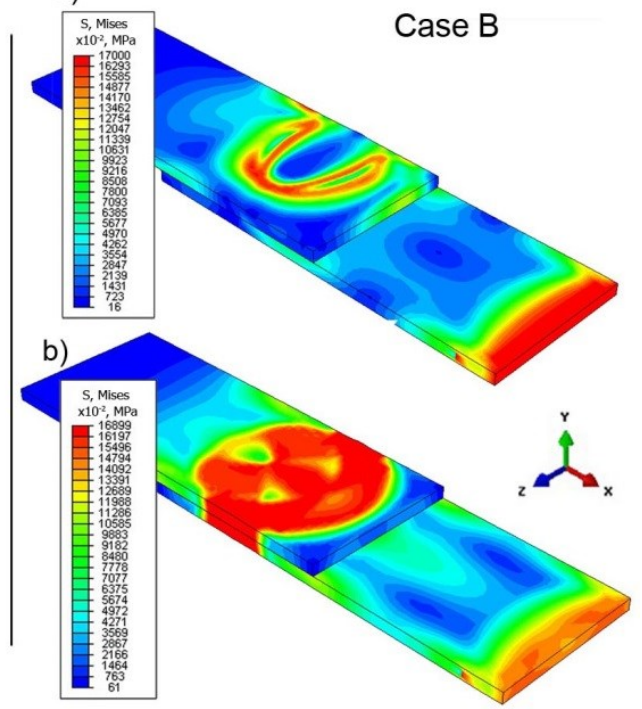

Fig. 9. Stress distribution (von Misses) for different welded times and boundary conditions, a) temporary stresses, b) residual stresses

From the analysis of results of reduced stress distributions for both cases of support it can be stated that stresses are almost identical in these cases. A completely different situation occurs in the case of displacement of the welded joint, presented in Fig. 10.

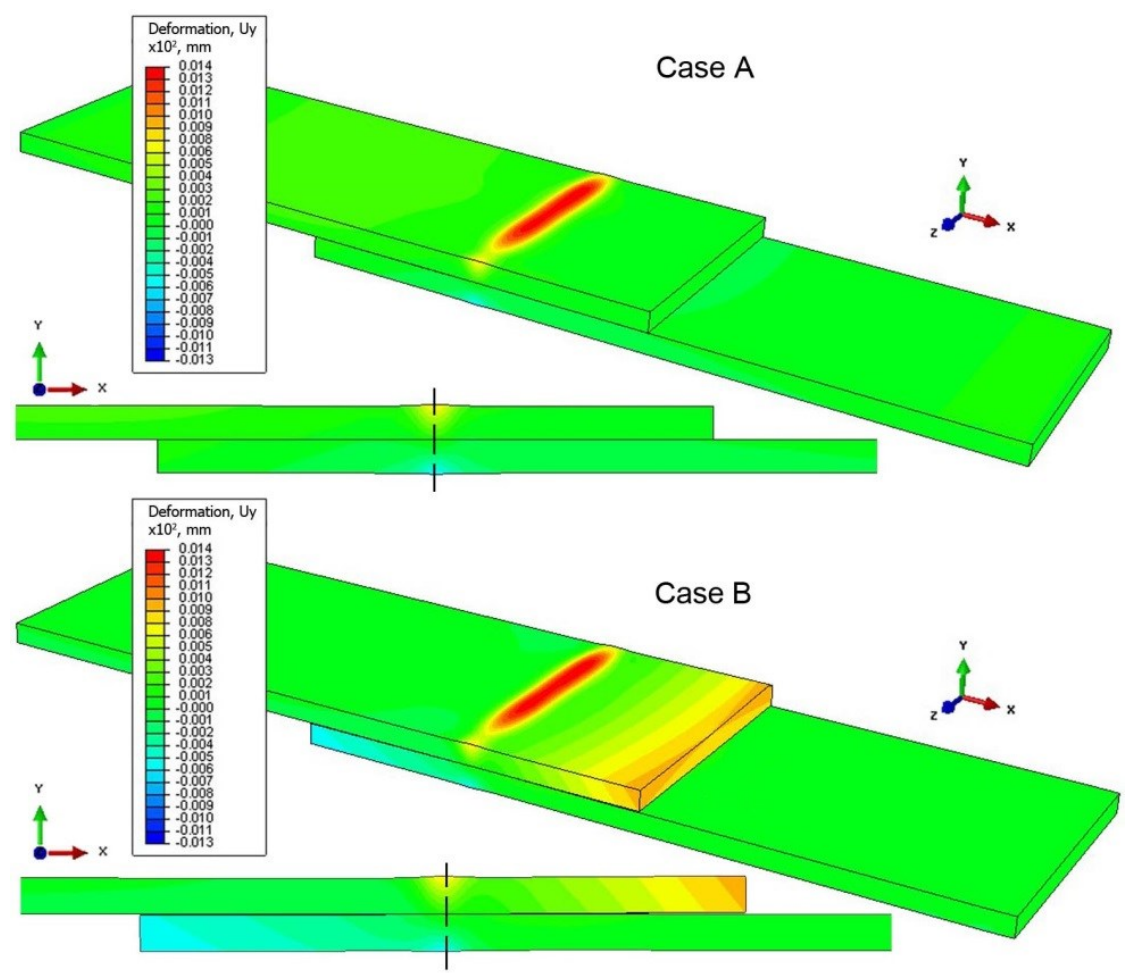

Fig. 10. Numerically estimated deflection $U_{Y}$ in laser welded lap joint for two case 
Assumed boundary conditions in Case A prevent free motion of the plate. In Case B, the free ends of the plate have the possibility to move which is reflected in the numerically estimated displacement presented in Fig. 10.

\section{Conclusions}

The paper presents an analysis of thermomechanical phenomena in welded laser lap joints using the Abaqus FEA software. The Abaqus has been completed by additional numerical subroutines allowing for a complete analysis of thermomechanical phenomena of the welding process. The appropriate contact conditions at the interface between joined elements are defined. The temperature distribution is determined in the lap joint. The melting zone, state of stress and welding deformation are estimated. The influence of the supporting method on stress and deformation of the joint is analyzed. In analyzed support cases the impact on the state of stress was relatively small (Fig. 9). Significant differences occurred in the fields of displacement (Fig. 10). Numerical simulations show that the developed numerical model can be a useful tool for preliminary design of laser welded lap joint.

\section{References}

1. S. Zhang, Stresses in Laser-Beam-Welded Lap Joints Determined by Outer Surface Strains. Welding Research, 14-18 (2002)

2. G. A. Moraitis, G. N. Labeas, Residual stress and distortion calculation of laser beam welding for aluminum lap joints. J Mater Process Tech. 198 (1-3), 260-269 (2008)

3. M. Hyrcza-Michalska, F. Grosman, The Research Of Laser Welded Blanks Characteristics In Basic And Technological Drawability Tests. $12^{\text {th }}$ International Conference on Metal Forming, Cracow, Poland, Steel Research International, 780-787 (2008)

4. J. Pilarczyk, M. Banasik, S. Stano, J. Dworak, Laser joining with wire filler material and mechanical seam tracing system. Przegląd Spawalnictwa 12, 9-14 (2011)

5. M. Kubiak, W. Piekarska, Z. Saternus, T. Domański, S. Stano, Simulations And Experimental Research On Laser Butt-Welded T-Joints. Metal 2014: $23^{\text {rd }}$ International Conference On Metallurgy And Materials, 726-731 (2014)

6. J. Ma, F. Kong, W. Liu, B. Carlson, R. Kovacevic, Study on the strength and failure modes of laser welded galvanized DP980 steel lap joints. J Mater Process Tech. 214 (8), 1696-1709 (2014)

7. W. Piekarska, M. Kubiak, Z. Saternus, Numerical Simulation of Deformations in TJoint Welded by the Laser Beam. Arch Metall Mater. 58 (4), 1391-1396 (2013)

8. M. Kubiak, W. Piekarska, Z. Saternus, S. Stano, T. Domański, Numerical Prediction Of Deformations In Laser Welded Sheets Made Of X5CrNi18-10 Steel. Arch Metall Mater. 60 (3), 1965-1972 (2015)

9. Y. Miyazaki, S. Furusako, Tensile Shear Strength of Laser Welded Lap Joints. Nippon Steel Technical Report 95, 28-34, (2007)

10. H. Wei, Q. He, J. S. Chen, H. P. Wang, B. E. Carlson, Coupled thermal-mechanicalcontact analysis of hot cracking in laser welded lap joints. J Laser Appl. 29 (2), (2016)

11. S. K. Choa, Y. S. Yanga, K. J. Sona, J. Y. Kimb, Fatigue strenght in laser welding of the lap joint. Finite Elements in Analysis Design 40, 1059-1070 (2004) 
12. A. Anca, A. Cardona, J. Risso, et al., Finite element modeling of welding processes. Appl Math Model 35, 688-707 (2011)

13. A. Sapietová, V. Dekýš, M. Sapieta, P. Pecháč, Application of computational and design approaches to improve carrier stability. Procedia Eng. 96, 410-418 (2014)

14. A. Sapietová, M. Sága, P. Novák, R. Bednár, J. Dižo, Design and application of multisoftware platform for solving of mechanical multi-body system problems. Mechatronics: Recent technological and scientific advances, 345-354 (2011)

15. SIMULIA, Abaqus FEA theory manual. Version 6.7, Dassault System (2007)

16. L. Sowa, Effect of steel flow control devices on flow and temperature field in the tundish of continuous casting machine. Arch Metall Mater. 60 (2A), 843-847 (2015)

17. W. Longa, Krzepnięcie odlewów w formach piaskowych. (Śląsk, Katowice, 1973)

18. T. Skrzypczak, E. Węgrzyn-Skrzypczak, Modeling of thermal contact through gap with the use of finite element method. J. Appl. Math. Comput. Mech. 14 (4), 145-152 (2015)

19. S. A. Tsirkas, P. Papanikos, Th. Kermanidis, Numerical simulation of the laser welding process in butt-joint specimens. J Mater Process Tech. 134, 59-69 (2003)

20. A. Bokota, T. Domanski, Modelling And Numerical Analysis Of Hardening Phenomena Of Tools Steel Elements. Arch Metall Mater. 54 (3), 575-587 (2009) 